\title{
A Preliminary Study on Challenges and Solutions for College EFL Education in Ethnic Minority Regions of China
}

\author{
Dianping Liu ${ }^{1}$, Sijia Xue ${ }^{2} \&$ Rong $\mathrm{Hu}^{3}$ \\ ${ }^{1}$ College of Foreign Languages, Yanbian University, China \\ ${ }^{2}$ Faculty of Education, The University of Hong Kong, Hong Kong \\ ${ }^{3}$ Faculty of International Business, Beijing Normal University, Zhuhai, China \\ Correspondence: Sijia Xue, Faculty of Education, The University of Hong Kong, Pokfulam Road, Hong Kong.
}

Received: December 8, 2018 Accepted: January 15, 2019 Online Published: January 18, 2019

doi: 10.5539/elt.v12n3p15 URL: https://doi.org/10.5539/elt.v12n3p15

\begin{abstract}
The internationalization of education brings different challenges to local education of different communities. Traditional EFL education in Chinese universities may also encounter such challenges. Against this background, this study investigates the challenges and solutions for college EFL education in ethnic minority regions of China. A narrative research method was conducted. Three college EFL teachers from three universities in China's ethnic minority regions were selected as participants. Interviews and document analysis were employed to collect data. Results by an inductive approach to qualitative content analysis showed that three aspects of challenge existed for EFL education in these regions, including financial, pedagogical and cultural. Solutions to these challenges suggested by the participating teachers included enhancing teaching methods, promoting teacher development and employing educational technology.
\end{abstract}

Keywords: EFL education, ethnic minority regions in China, challenges, solutions

\section{Introduction}

English as a foreign language (EFL) has been taught in China for over one century. With the political and economic development in China, EFL education has also experienced different stages in its evolution. Currently, English has become one of the compulsory courses in all universities and numerous tests associated with English have become a requirement to secure graduation and a standard to evaluate a graduate's qualification. However, EFL teaching in China's tertiary education is encountering many dilemmas for long time, which may be even more challenging in ethnic minority regions. On the one hand, traditional teaching mode stresses teacher's role and pays too much attention to textbooks and examinations (Gao, 2012). On the other, with few opportunities to use the language in reality, learners' communicative competence is not fully fostered and their learning motivation declines as a result. Meanwhile, due to the imbalance of economic development, there exists huge gap in EFL education between ethnic minority and Han regions (Rong, 2006). With the advance of internationalization of education, it is pressing to make alteration in EFL education at tertiary level to balance the global and local needs. Against such a background, this study aims to explore the existing issues on EFL teaching and learning in ethnic minority areas of China. Particularly, two research questions are focused on: 1) what are the major challenges for EFL education in ethnic minority regions of China? 2) what are the possible solutions to these challenges?

\section{Current Issues in EFL Teaching in China's Higher Education}

Generally, current issues about EFL teaching in China's higher education can be interpreted from both teaching and learning aspects. The former mainly indicates the traditional teaching mode, which is problematic in cultivating learners' language competence; while the latter refers to the challenges for learners per se. In this section, these issues will be discussed in detail.

\subsection{Traditional Teaching Mode}

A traditional teaching mode is still dominant in EFL instruction in China's tertiary education, featuring teacher-centered, textbook-centered and test-centered. Generally, teachers are deemed as the center of the whole class and they possess the authority to decide what to teach and in what way they instruct. Under most 
circumstances, too much attention is paid to form-teaching, a more grammar-oriented language teaching way that the teacher focuses mainly on grammatical rules and the meaning of words. Teachers spend large quantity of time analyzing sentence structures and theoretical knowledge that are the major parts of most English textbooks, overlooking how to apply the language in practice. Based on a centralized curriculum system, the majority of textbooks adopted for EFL education are designed for grammar teaching, emphasizing reading and writing rather than listening and speaking, which means the source materials are not sufficient and authentic enough for learners to enhance their language proficiency (Rao, 2013).

Another aspect of traditional teaching mode is reflected in the fact that English teaching in China's universities is basically test-centric. Since 2000, undergraduate students (non-English majors) have to pass different English proficiency tests such as CET-4 (College English Test Band Four) in order to obtain a Bachelor's degree and secure a decent job after graduation (Gao, 2011). Therefore, they are pushed to acquire the language as the teacher expects and requires, which mainly serves for examinations. In addition, they are offered few opportunities to think critically and practice creatively as all they need to do is sitting there taking notes, passively receiving what the teacher is delivering in the classroom, and memorizing (Chen \& Ding, 2011). As a result, they become knowledge recipients other than language user, which not only triggers the increasing decline in their learning motivation (Liu, 2012) but also the deficiency in their language proficiency, particularly in their communicative competence. However, communication has been regarded as the heart of $21^{\text {st }}$ Century Skills (Framework for $21^{\text {st }}$ Century Learning). In order to better meet the requirements for talent cultivation under educational internationalization, it is the responsibility of education in every country to equip local population with excellent communicative competence.

\subsection{Demotivated Learners}

Old fashioned teaching mode leads to problems in learners (Chen \& Ding, 2011). On the one hand, students are taught with more linguistic knowledge than linguistic competence, which gives rise to their insufficient language skills in terms of communication. In other words, students learn the language mainly for passing examinations rather than using it as a tool. This is largely due to the fact that there are few opportunities for learners to use English in reality, particularly to use it in face-to-face communication (Liu, et al., 2016). According to a survey, only 7\% of Chinese EFL learners utilized English "often" whereas 69\% "seldom" used the language (Bolton \& Botha, 2015). It seems that the actual use of English is restricted to only a very small number of populations in reality. For the majority of college students $(65 \%)$, the most possible scenario for them to employ English is in school, while most of them (64\%) have no opportunities to use the language out of school. This is even more true for those students who live in small cities or remote areas where few foreigners reside (Liu et al., 2016). However, studies have also found that these college students tend to seek opportunities for themselves to practice the language through watching English films, browsing English websites and attending English parties with their foreign teachers (Liu et al., 2016). Therefore, it is apparent that one of the major challenges for EFL teaching in China's higher education is how to create more contexts for the students to apply the language thus to truly master the language.

On the other hand, the deprivation of practicing opportunities may affect learners' learning motivation. It is revealed that Chinese university students are instrumentally motivated to learn English (Liu, 2012). This means that they learn the language out of external forces other than internal satisfaction. For instance, they may learn for better academic performance and future careers but not for personal liking of the language. This tendency is more evident in those institutions where students are required to pass the CET-4 in order to graduate on time (Liu, 2012). Motivation is the internal force for learning and is correlated with learning performance. However, driven by examinations rather than communication, Chinese college students are coerced to learn English instrumentally. By contrast, they should be motivated to acquire the language with integrative purposes, which is the impetus of successful learning and drives the students to apply the language in real-life communication (Gardner, 1985).

\subsection{Ethnic Minorities in China}

China is a multi-ethnic nation, with Han Chinese making up the majority $(91.46 \%)$ of the population and the other officially 55 minority ethnic groups accounting for the rest (8.54\%) (National Bureau of Statistics of China, 2015). These ethnic minority groups have their unique languages, costumes, festivals, customs, and distribute at different regions across China. For example, Zhuang people, as the largest ethnic group, live mainly in the south and southeast, in particular Guangxi province. The PRC's Constitution and laws guarantee equal rights to all ethnic groups in China and help promote ethnic minority groups' economic and cultural development, including the use and development of their own languages. In some regions, local minority languages are official working 
language in administration, broadcasting, publication and schools. In terms of education, a comprehensive educational system from kindergarten to higher education has been established in these ethnic minority regions. However, education in these areas still lags far behind that of most other regions in China in many aspects of educational development. The reasons for such differences are multifaceted, including historical, socio-cultural, economic and policy (Yang \& Wu, 2009).

\section{Research Methodology}

\subsection{Participants}

This study focuses on the current situations of EFL education at the tertiary level in ethnic minority regions of China. Particularly, major challenges teachers are encountering and possible solutions to these challenges were explored. Three College English teachers from three universities in China's ethnic minority regions participated in this investigation for data collection. One was from a northeastern university of China, where Korean (Chinese ethnic group) students were centralized. The second was teaching in a northwestern university of China, where Muslim students such as Hui students were the major minority. The third teacher was selected from a university in the Southwest of China, where diverse ethnic minority students were coexisting. To some extent, these three regions represented the major areas where ethnic minority people densely inhabited in China. Thus, the data collected from these three teachers, to some extent, could probably reflect the present situations of College English education in China's ethnic minority regions. These three universities were purposively selected based on their geographical location where students of different ethnic minorities were centralized but the teachers were selected randomly among all the teaching staff in their departments. Emails attached with consent forms were sent to six teachers in these three universities, two for each. Three of them replied to the email and agreed to participate in this study after further inquiry. The demographic information of these three teachers are presented in the table below (see Table 1). Considering the privacy issue, pseudonyms were used in this study.

Table 1. Demographic information of participating teachers

\begin{tabular}{cccc}
\hline Identifiers of participants & Gender & Regions & Years of teaching \\
\hline WLH & Female & Northeast & 20 \\
LM & Female & Southwest & 10 \\
ZXY & Female & Northwest & 5 \\
\hline
\end{tabular}

\subsection{Data Collection Methods}

Narrative research was conducted to address the research questions. Narrative has emerged as a method in educational research for its salient features (Xu \& Liu, 2009). Through telling and retelling, living and reliving teachers' own stories, teachers' lived experiences, including their knowledge and practices, can be interpreted and understood narratively (Clandinin \& Connelly, 1996; Craig, 2007). Two sets of semi-structured interviews were performed for each participating teacher. One focused on the challenges they were encountering in their EFL teaching; the other focused on the possible solutions for these challenges. Each interview lasted for about two hours. All the interviews were conducted in Chinese, in order to allow the participating teachers better express themselves. The interviews were first transcribed verbatim and then translated into English. In order to strengthen the validity of the findings, member checking (Merriam, 1988) was conducted. Both Chinese and English transcripts were sent to the corresponding participating teacher for confirmation.

Moreover, document analysis was utilized to confirm what had been identified from the interviews and to further understand the emergent issues. The documents included teachers' course outlines and lesson plans; governmental and institutional documents issued regarding college EFL teaching in minority regions, such as College English Curriculum Requirements (2007); and statistical data related to ethnic minority regions that was collected from the official website of National Bureau of Statistics of China (http://www.stats.gov.cn). Such physical traces can not only check on information obtained from interviews, but also help researcher know about the inner meaning of everyday events and generate descriptions of rare and extraordinary events in participants' life (Merriam, 1988).

\subsection{Data Analysis}

An inductive approach to content analysis (Thomas, 2006) was utilized for data analysis. First, units of analysis were identified for open coding by scrutinizing each transcript. After completion of the open coding, preliminary 
codes emerging from the texts were determined and then the transcripts were coded with these codes. When data did not accommodate an existing code, new codes would be added. Next, similar codes were grouped and placed into categories, which were revised, refined, and checked until they were mutually exclusive to form the final categories. The last step was to identify the relationships among the categories to generate themes. Situations reflected by each teacher were analyzed first and then all the reflections were synthesized to identify similar patterns and generate final conclusions (Yin, 2003). For example, after open coding, "Internet-based lab" was identified as a code in one participating teacher's transcript. Both "MOOCs and flipped classroom" were identified as new codes in the other two teachers' narratives. Then a category of "technology" was formed by identifying the relationship between these codes. After referring to the document (College English Curriculum Requirements, 2007), a theme emerged that was "employing educational technology". Discrepancies were discussed by the researchers until consent was reached. No prior assumptions were generated before the analysis. The results emerged inductively from inspecting and interacting with real data.

\section{Results}

In this section, challenges for college EFL education in China's ethnic minority regions and relevant solutions are explicated based on data analysis. The challenges were embodied in three aspects: financial, pedagogical and cultural; whereas the solutions were also suggested from three dimensions: teaching methods, teacher development and technology integration.

\subsection{Challenges for College EFL Education in Ethnic Minority Regions}

\section{Financial challenge}

To begin with, financial shortage was the biggest challenge for college EFL education in these ethnic minority regions. The shortage could attribute either to the overall economic level of the regions or to the limited attention paid to EFL education by the government. According to statistics, the national average GDP per capita in minority regions was 33003 RMB (4809 USD), compared with 65170 RMB (9497 USD) in the eastern developed areas (National Bureau of Statistics of China, 2013), which indicates there is a huge gap in finance between minority and non-minority areas. The financial gap directly affected the investment of educational funding by the local government. Particularly, the central government launched educational reform to decentralize education administration since 1980s, which imposed huge financial burden to the local government in minority regions. While this implementation, to some extent, has relieved the responsibility on the part of the central government, the gap in financial resources between the minority regions and Han regions has widened. Due to the differences in social and economic development, many ethnic minority areas have been left struggling with their educational financial responsibility (Postiglione, 2000).

Inadequate educational funding resulted from the financial burden could be identified in many aspects, such as teaching and learning resources. Compared with eastern coastal regions such as Shanghai, where interactive networking of classrooms across different universities has been realized through online link in 2000s, the teaching facilities in many institutes in minority regions are out-of-date (Jin \& Cortazzi, 2003). Another manifested aspect was learning resources for students. In minority regions, there were very limited English learning resources such as reading materials and students had few opportunities to practice English in their communities. Such situations might be aggravated by economic factors, which was confirmed by LM:

"The economic conditions limit the accessibility of learning resources available for these minority students. For example, when I recommend books for the class, these (minority) students need to take full consideration on the selection and purchase of the books because they cannot afford to buy them all. By contrast, those students living in developed urban areas have advantages over these minority students as they have more opportunities and resources to develop their language abilities, such as communicating with English native speakers."

Moreover, insufficient attention paid to EFL education in these minority universities was another contributing factor. In fact, in some minority institutions, EFL education tended to be peripheralized. As WLH stated:

"While the government supports the development of the university, less funding can be assigned to our department as College English teaching is being peripheralized in our university. I think the prospect of College English teaching is not positive, at least in our university. As you may have heard, the teaching hours of many College English teachers have already been cut down. In fact, this (College English) is a disadvantaged discipline."

Similar statements were also made by the other two teachers. Therefore, it can be noted that lack of financial support caused by both local economic conditions and institutional indifference has negatively impacted the EFL education in minority universities. 


\section{Pedagogical challenge}

The teaching model of EFL education in ethnic minority regions brought another challenge. Since the reform and opening-up policy, central government has advocated bilingual education throughout the nation, which refers to teaching in both Chinese and English. However, this is relatively challenging for ethnic education in that the medium of instruction employed may not match the language used to write the textbooks. On the one hand, in order to increase attendance rates and enhance socialization into national ideologies, minority teachers tend to use ethnic languages as a medium of instruction (Yang \& Wu, 2009). On the other hand, the textbooks adopted are normally not designed for minority students but for Han students in terms of language and culture, which makes learning English even more demanding in that minority learners may need to process in three languages before completely understand what the teacher really wants to instruct. Such trilingual transference in EFL learning is likely to incur the reduction in minority students' learning motivation and cultural awareness (Jiang, et al., 2005). This, in turn, will definitely affect their language competence. The issues manifest themselves when these minority students enter college, which have caused enormous challenge for EFL teachers in ethnic minority universities. As WLH said:

"Generally, Korean students are outgoing and good at a lot of things such as singing and dancing. However, they are very passive and shy in English class due to their low language proficiency and some of them even cannot express themselves clearly in Chinese because they graduated from ethnic high schools where their native language was the only medium of instruction. In fact, English is the third language for them and the negative transfer of Korean language is very apparent in their learning, particularly in their English writing. ... Personally, the biggest challenge for me is how to instruct these group of (minority) students and help them pass the (CET) exams as their passing rate is really low."

According to the description above, it can be noted that to some extent these minority students are less motivated to learn English as passive learners. The lack of motivation in these minority learners even increases the challenge on teachers in terms of teaching. As ZXY pointed out:

"Some of these minority students are quite passive learners, which makes teaching even more challenging. ... and I think the fundamental reason for the demotivation of these minority students in learning English is that they hardly have any opportunities to use the language after class unless they are really interested in the language."

While some minority students are motivated, their personal language proficiency caused by the teaching mode in their local context has become an obstacle for college EFL education. This can be reflected in LM's expression:

"Actually, some minority students are motivated to learn English as this is one of the most direct ways for them to get rid of their poor living conditions. They may find a decent job after graduation suppose they could pass CET-4.... However, these students are struggling with their English learning (pronunciation in particular) for the negative transfer from their native languages as English is the third language for them."

Therefore, it can be observed that the teaching mode of EFL education rooted in these minority regions has become a huge challenge for EFL teachers when these minority students learn English at the tertiary level.

\section{Cultural challenge}

Another challenge for College EFL education in ethnic minority regions reflected by the participating teachers was culture related. This type of cultural challenge mainly stemmed from the conflict between English culture that was demonstrated through EFL education and the native cultures of these minority students, particularly in the aspect of religion. As ZXY related:

"I have to be very cautious if there are Hui students in my class and be very careful when I am translating some words such as 'pork'. I also need to be cautious in the selection of topics for writing exercises, avoiding to mention any sensitive thing related to religion. The university always reminds us to respect minority students but this is really challenging for me because some minority students are radical. Whenever I see a student wearing a prayer cap in my class, I feel nervous for fear that I might mention something culturally sensitive to them .... In other words, the cultural issues are the biggest challenge for me."

Similarly, LM also mentioned such a challenge emerging in her teaching:

"Cultural impact from their (minority students') own cultures is also apparent. Some values and views manifested in English culture may conflict with theirs. For instance, it is very hard for some minority students to accept the concept of gender equality, which is rare to see in their culture. Also, since many minority people live together in tribes, some minority students cannot understand the living styles or values reflected in western 
cultures, such as individualism. I think this matters because learning a language is learning a culture. But it is not easy for some minority students to accept English culture even though they are learning English language."

Based on the accounts above, it can be seen that another challenge for EFL education in ethnic minority regions is culture-oriented. Particularly, how to make ethnic minority students better understand English culture reflected from the language teaching is challenging for teachers.

\subsection{Suggested Solutions for College EFL Education in Ethnic Minority Regions}

Considering the aforementioned challenges, relevant solutions were also suggested by the participating teachers. These solutions can be categorized into three dimensions, including teaching method, teacher development and technology integration.

\section{Enhancing teaching methods}

To enhance teaching methods in order to better accommodate the characteristics and needs of ethnic minority students has been regarded as the most direct way to improve the current situations by all the participating teachers. The enhancement could take place either by an individual teacher or by the institution as a whole. For example, WLH narrated how she was attempting to make changes herself:

"Personally, I design some teaching and learning activities that may involve the cultural elements of minority students to encourage their participation in teamwork with Han students. I think they are "disadvantaged" in terms of English learning. Thus, we need to allow for their feelings and design some activities to maintain their learning interest and promote their confidence. Besides, I think the accessibility of textbooks or learning materials with diverse cultural elements and features particularly designed for these group of students should be helpful even though that would be hard to realize."

Meanwhile, she also related how their department attempted to reform college EFL teaching for minority students:

"We tried to make some changes in our teaching for these minority students. For example, a couple of years ago, we adopted "stratified teaching", by which students were allocated into different classes according to their English proficiency levels but it did not work well because we also need to consider the situations of Han students. However, I think formative assessment allowing for the different characteristics of these group of (minority) students may be necessary. Now, we are working on new plans for College English teaching because we have to change under such pressure. For example, we are trying to modify the course design, combining common English courses with more elective courses such as cross-cultural communication to provide more options for (minority) students."

By contrast, LM believed that teachers could enhance their teaching outcomes through the design of teaching and learning activities:

"While it is less likely for teachers to adjust their teaching through the adoption of teaching contents and materials, or approaches particularly for minority students, they can encourage these students to select topics related to their cultural features during learning activities and task completion, and to share their own cultures with other classmates, in order to motivate these minority students."

Both teachers also presented their course outlines and lesson plans to demonstrate the teaching contents they selected and learning activities designed, particularly for ethnic minority students. Below is an excerpt from WLH's lesson plan:

\begin{tabular}{lllll}
\hline $\begin{array}{l}\text { Teaching } \\
\text { steps }\end{array}$ & Teaching contents & $\begin{array}{l}\text { Teacher } \\
\text { activity }\end{array}$ & Student activity & Teaching objectives \\
\hline $\begin{array}{l}\text { Pre-sessional } \\
\text { activity }\end{array}$ & $\begin{array}{l}\text { Role-play: } \\
\text { Intercultural } \\
\text { communication }\end{array}$ & $\begin{array}{l}\text { Teacher } \\
\text { monitoring \& } \\
\text { scaffolding }\end{array}$ & $\begin{array}{l}\text { Collaboration between Han } \\
\text { and minority students to collect } \\
\text { materials and rehearse for } \\
\text { video making or role-play. }\end{array}$ & $\begin{array}{l}\text { Brainstorm, } \\
\text { communication \& } \\
\text { collaboration }\end{array}$ \\
Lead-in & $\begin{array}{l}\text { Role-play } \\
\text { performance }\end{array}$ & $\begin{array}{l}\text { Follow-up } \\
\text { discussion }\end{array}$ & Peer review \& self-review & $\begin{array}{l}\text { Comprehensive } \\
\text { ability of using the } \\
\text { language }\end{array}$ \\
\hline
\end{tabular}




\section{Teacher development}

All the participating teachers suggested that opportunities for teacher professional training and development were crucial to help resolve the existing challenges in EFL education. As LM said:

"For these groups of minority students, I think what they need is basic education, not only in terms of learning materials but also qualified teachers. Actually, well-qualified English teachers are very vital for these minority students to enhance their language learning. For example, the government can provide more opportunities to these minority English teachers for their professional development through different programs. Some of my friends who are teaching in other minority universities have been sent to English speaking countries such as Britain, America and New Zealand for professional training. I think this is really essential. I don't think it is necessary for the government or institutes to issue particular policies for these minority students in order to reduce their pressure, say, to lower the criteria for pertinent English exams. However, I do believe we should try to solve the issues by promoting our teaching through training teaching staff to better meet these minority students'needs. This is the fundamental thing".

Similarly, WLH was also convinced that professional development for teachers was important:

"Since most of the teachers in our department are getting on in years, it is really challenging for them to learn new things such as the operation of a new teaching system or the acceptance of a new teaching concept. However, the good thing is that we are offered some opportunities for professional training and we have established a teacher development center for this".

This was also echoed by ZXY, who described the situations in her university:

"In recent years, the university encourages teachers, particularly young teachers to participate in various professional training on new teaching approaches such as flipped classroom. More opportunities have been provided for teacher development in order to help teachers better teach these minority students. I think it is useful".

Based on these statements, it was apparent that teachers were positive to professional training and development, which was deemed supportive for them to deal with the challenges they were encountering in terms of EFL teaching in minority regions. This was also confirmed by a recently issued document from one participating teacher's university. The university was organizing a training program for college English teachers, which was cooperated with British Council in order to develop the teachers' professional knowledge and competence of teaching English in ethnic minority regions.

Employing educational technology

While still in its infancy, technology-assisted College English teaching was emerging as a new approach in different universities. However, the adoption of such innovative teaching might involve certain demands on teachers. As WLH told:

"We are also promoting technology-assisted teaching such as MOOCs (Massive Open Online Courses) and flipped classroom but actually we are still learning. From long run, I think it should be useful despite that we are also concerned about the challenges involved in the acceptance and implementation of such teaching approaches. For example, some teachers think they are too old to learn these new things. However, personally, I think this is a trend that technology should be integrated with teaching. This is also for the accommodation of students' needs since they were born "digital natives". Therefore, an incentive mechanism (from the university) is very crucial for the promotion of such innovation (integration of technology into teaching)".

LM also depicted the situations in her department, where educational technology has been integrated into daily teaching:

"Technology has already been integrated into College English teaching for these minority students in our department. For example, in terms of teaching English listening, we have an Internet-based lab where students can choose from a selection of platforms that they are interested in to practice their listening. The selection is based on their own English language proficiency and the assessment is based on their selected platforms".

Likewise, technology-enhanced EFL teaching was also being practiced in ZXY's university:

"The university encourages us to participate in various trainings for our professional learning, particularly those related to technology-enhanced teaching, such as MOOCs and flipped classroom. Although it began only in this year, I think it is really useful because students 'learning interest has increased".

In fact, it has been advocated by the central government for over a decade that College English teaching should 
make the best of modern technologies even though the implementation of the policy is less than desirable. As indicated in the College English Curriculum Requirements (2007):

"...All the institutions of higher learning should adopt computer-based classroom teaching mode to improve the traditional teaching mode that features teacher-centered instruction. The new teaching mode should be supported with modern information and communication technologies, in particularly internet technology, in order to break the limits of time and space for English teaching and learning..."

It could also be seen from the participating teachers' narratives that the integration of educational technologies with EFL education tended to facilitate their teaching in that not only more learning resources were accessed but learners' learning interest was also promoted. However, both teachers and teaching facilities need to be well prepared for such an innovation.

\section{Discussion}

Concerning the challenges for EFL teaching in China, Wu (2001) suggested the direction to reform. First, appropriate English teaching plan should be made to accommodate diverse learners. Secondly, teacher education is crucial for enhancing EFL teaching, including the development of teachers' English proficiency levels and their teaching philosophy and approaches. Moreover, traditional teaching materials should be effectively associated with technologies like multimedia to address the lack of source materials. These suggestions may also be applicable to ethnic minority regions, thus could be adopted to address the relevant issues about EFL education in these regions.

\subsection{Reforming Teaching Methods}

Given the defects of traditional EFL teaching mode in China's higher education, the pressing need is to reform teaching methods. One of the optimal approaches to teach English in the future is to "reconcile Communicative Language Teaching (CLT) with traditional Chinese teaching methods" (Rao, 2013, p. 37). While there is no consent on the definition of CLT, the nature of such a teaching approach emphasizes the use the language and communicative competence of learners. After all, the primary goal of language learning should be application of the language. This is particularly important for EFL teaching in ethnic minority regions. As Postiglione (2008) points out, against the background of globalization, it is self-evident that ethic minority communities must promote their competency in three entirely different languages: the native, the national (Chinese) and the international (English) in order to survive from a long run. CLT requires the shift of a teacher-oriented teaching mode into a student-centric one, in which both linguistic knowledge and communicative competence should be stressed. In addition, as a significant component of communicative competence, cultural awareness can also be promoted in learners through CLT, which is even more significant for ethnic minority learners.

The reform of teaching approach involves efforts from different respects. Initially, teachers should change the concept of their own role from being a knowledge disseminator to being a multi-role educator; recognizing that language learning not only means the acquisition of linguistic knowledge but also includes the cultivation of comprehensive competence (Littlewood, 2013). Teaching should aim to enhance learners' motivation as well as engagement and be student-oriented so as to promote their holistic competence. Meanwhile, the adoption of an innovative teaching approach such as CLT should consider the local contexts, including culture, setting, teachers' perceptions and practices, to create meaningful learning experiences and outcomes.

\subsection{Establishing Favorable Policies}

Besides the reform of teaching approaches, issues pertaining to EFL education in ethnic minority areas are likely to be mitigated through policy-making. Present policies regarding language education are promoted and institutionalized by systemic tools, through which a hierarchical structure privileging competence in English and graduates from elite universities has been established (Adamson \& Xia, 2011). As a result, negative impacts have been exerted on minority languages as well as their cultures, and to some extent this is unfair to minority students. Thus, more legitimate policies should be made, allowing for the unique features and practical problems of EFL teaching in ethnic minority regions. In fact, Chinese government has been committing to the educational development in ethnic minority areas since 1950 (Yang \& Wu, 2009). One of the salient characteristics of these measures is to take full advantage of the central state to serve for ethnic minorities (Yang \& Wu, 2009). Northwest Ethnic Teachers' Training Center and Southwest Training Center for Ethnic Teachers of English have been established in order to train ethnic teachers. Some research institutes and information centers have also been founded for studying ethnic education at different levels and for policy-making (Yang \& Wu, 2009). The shortage of qualified English teachers is one of the severe issues of EFL education in minority regions. Generally, the English teachers in these regions received less professional development training due to various reasons such 
as financial difficulties. Despite the fact that there are many normal colleges and universities in these areas, very few of them provide professional preparation programs such as a $\mathrm{PhD}$ program in English language education (Yang, 2008). Therefore, such training centers are of particular importance for EFL teacher development in ethnic minority regions.

However, other aspects should also be considered in addition to teacher training. Curriculum policy should be modified through decentralizing curricula and syllabuses to encompass more materials related to local cultures, histories, geographies, literature and arts of the ethnic minorities (Yang \& Wu, 2009). More locally-based textbooks should be compiled and introduced to better accommodate the needs of local practitioners. For example, English for Tourism featuring indigenous cultures can be developed, which will not only facilitate the acquisition of language competence in practice but also bolster minority students' cultural identity. Also, explicit trilingual teaching model and policy should be established to balance the multiple languages and cultures in such regions and to achieve equality of opportunity for ethnic minority students. Furthermore, collaborative and ameliorative policies should be considered regarding the educational financial issues. More funding needs to be invested to ethnic minority regions for the construction of modern educational environment, including up-to-date teaching facilities and abundant teaching materials.

\subsection{Integrating ICT Into EFL Education}

College English Curriculum Requirements (2007) suggests that EFL teaching in higher education should make full use of modern technologies such as information and communication technologies (ICT). Technology-assisted language teaching has been deemed to be effective in enhancing learners' language competence for many reasons. First, the connection of ICT to teaching alters traditional teacher-centered learning into student-centered learning, promoting learners' learning motivation. The roles of teachers are changed from being a dominator to being a facilitator, who directs students to learn independently in an innovative learning environment (Sun, 2013). As indicated in the Requirements, one of the teaching objectives of EFL education is to foster learners' autonomy to learn independently.

Secondly, more interaction between teachers and students can be achieved due to the salient features of modern technologies, particularly mobile technologies like tablets and smartphones. This is of particular importance for language acquisition, especially for ethnic minority regions where few opportunities are available for students to practice English outside the classroom because learners are able to use the language through various social networking services created by technologies. Moreover, such technology as internet connectivity provides abundant of learning resources, which can complement the shortage of teaching materials in traditional teaching (Churchill, 2017). This is even more significant for minority areas where learning materials are inadequate and occasions for communication in English are very limited. It has been revealed by study that in ethnic minority regions, students have reflected strong inclination to communicate with foreign friends through blogs and internet (Lu, 2013).

However, the implementation of technology-assisted language teaching involves various practical obstacles. While it has been proposed in the Requirements that ICT should be exploited in EFL teaching, there are no explicit elaborations guiding the implementation. There seems to be a conflict between the theory and the responses from both administrators and teachers in practice (Gao, 2012). Such application by practitioners needs not only the support from policy-makers on curriculum design but also professional training related to ICT competence as insufficient capacities of teachers and technical support from the institutions may impede the application of technologies into teaching practice (Hu \& McGrath, 2011). In brief, modern educational technologies can be employed to construct a more ideal EFL learning environment in ethnic minority regions and to enhance minority learners' autonomy, yet support from different parties is demanded for smooth implementation including financial support from the government for the purchase and maintenance of facilities.

\section{Conclusion}

To conclude, traditional mode of college EFL education in ethnic minority regions of China can hardly meet the needs brought by the internationalization of education. The challenges mainly manifest in three aspects, including financial, pedagogical and cultural. To cultivate capable local talents equipped with essential communication competency, there is a pressing demand to reform the present EFL education in these regions. Student-centered and application-oriented teaching method such as CLT could be adopted with the purpose of enhancing minority learners' holistic competence. Modern technologies could be integrated into EFL education in these areas to complement the lack of teaching resources and practicing opportunities, and to promote minority learners' motivation. Professional training programs should be offered to practitioners to ensure the implementation of teaching innovation. In addition, due attention should be paid to EFL education in ethnic 
minority areas through policy-making and financial support in order to narrow regional gaps. New teaching model featuring minority languages and cultures should be established to accommodate the needs from both local and global communities. While this study is merely a preliminary exploration, insightful implications have been generated for college EFL education in ethnic minority regions of China. However, the sample size is small in this study. Also, this study has limitations in its data sources, with interviews and documents analysis being the major means for data collection. Future research could be conducted with larger sample size and more sources of data, in order to provide a panoramic picture of EFL education in China's ethnic minority regions.

\section{Acknowledgements}

This study was supported by General Project of Social Science Foundation of Jilin Province, China (2018B37).

\section{References}

Adamson, B., \& Xia, B. (2011). A case study of the College English Test and ethnic minority university students in China: Negotiating the final hurdle. Multilingual Education, 1(1), 1-11. https://doi.org/10.1186/2191 $-5059-1-1$

Average GDP per capita in east and west of China. Retrieved from http://data.stats.gov.cn/easyquery.htm? $\mathrm{cn}=\mathrm{C} 01 \& \mathrm{zb}=\mathrm{A} 010503 \& \mathrm{sj}=2013$

Bolton, K., \& Botha, W. (2015). English in Contemporary China [Special Issue]. World Englishes, 34(2), 169-174. https://doi.org/10.1111/weng.12131

Chen, Y., \& Ding, L. (2011). Analysis and strategies of present-day China's English education. 2011 IEEE 3rd International Conference on Communication Software and Networks, 690-693.

Churchill, D. (2017). Digital Resources for Learning. Singapore: Springer. https://doi.org/10.1007/978-981-10 $-3776-4$

Clandinin, D. J., \& Connelly, F. M. (1996). Teachers' professional knowledge land- scapes: Teacher stories-stories of teachers-school stories—stories of schools. Educational Researcher, 25(3), 24-30. https://doi.org/10.2307/1176665

College English Curriculum Requirements. (2007). Shanghai: Foreign Language Education Press.

Craig, C. J. (2007). Story constellations: A narrative approach to contextualizing teachers' knowledge of school reform. Teaching and Teacher Education, 23, 173-188. https://doi.org/10.1016/j.tate.2006.04.014

Framework for $21^{\text {st }}$ Century Learning. Retrieved from http://www.p21.org/our- work/p21-framework

Gao, L. (2012). Digital technologies and English instruction in China's higher education system. Teacher Development, 16(2), 161-179. https://doi.org/10.1080/13664530.2012.667967

Gao, Y. (2011). Development of English Language Education in Ethnic Minority Schools in Inner Mongolia Autonomous Region. Intercultural Communication Studies, 20(2), 148-159.

Gardner, R. C. (1985). Social psychology and language learning: The role of attitudes and motivation. London, Ontario: Edward Arnold. https://doi.org/10.1111/j.1467-1770.1985.tb00359.x

Hu, Z., \& Mcgrath, I. (2011). Innovation in higher education in China: Are teachers ready to integrate ICT in English language teaching? Technology, Pedagogy and Education, 20(1), 41-59. https://doi.org/10.108 0/1475939X.2011.554014

Jian, Y. (2005). English as a Third Language among China's Ethnic Minorities. International Journal of Bilingual Education and Bilingualism, 8 (6), 552-567. https://doi.org/10.1080/13670050508669068

Jiang, Q., Liu, Q., \& Li, Z. (2005). An Investigational Study of EFL Education in Ethnic Minority Areas of Gansu Province in Northwest China. Foreign Language Teaching and Research, 38(2), 129-135.

Jin, L., \& Cortazzi, M. (2003). English language teaching in China: A bridge to the future. In H. W. Kam, \& R. Y. L. Wong (Eds.), English Language Teaching in East Asia Today (pp. 131-145). Singapore: Eastern University Press.

Littlewood, W. (2013). Developing a Context-Sensitive Pedagogyisêpifor Communication-Oriented Language Teaching. English Teaching, 68(3), 3-25. https://doi.org/10.15858/engtea.68.3.201309.3

Liu, M. (2012). Motivation in Chinese University EFL Learners in Varying Learning Contexts. TESL Reporter, $45(2), 17-39$.

Liu, N., Lin, C., \& Wiley, T. (2016). Learner Views on English and English Language Teaching in China. 
International Multilingual Research Journal, 10(2), 137-157. https://doi.org/10.1080/19313152.2016.114 7308

$\mathrm{Lu}$, J. (2013). English learning in Chinese minority areas: The challenges and new directions. Theory and Practice in Language Studies, 3(4), 556-563. https://doi.org/10.4304/tpls.3.4.556-563

Merriam, B. S. (1988). Case study research in education. San Francisco, CA: Jossey-Bass.

Postiglione, G. A. (2008). Making Tibetans in China: The educational challenges of harmonious multiculturalism. Educational Review, 60(1), 1-20. https://doi.org/10.1080/00131910701794481

Postiglione, G. A. (2000). National minority regions: Studying school discontinuation. In J. Liu, H. A. Ross, \& D. P. Kelly (Eds.), The Ethnographic Eye: Interpretive Studies of Education in China (pp. 51-72). New York: Falmer Press.

Rao, Z. (2013). Teaching English as a foreign language in China: Looking back and forward. English Today, 29(3), 34-39. https://doi.org/10.1017/S0266078413000291

Rong, M. (2006). Education of Ethnic Minorities of Contemporary China. International Symposium on China's Positive Policies in Minority Education: Plural Perspectives, Dickinson College, USA, (April 14-15, 2006). Retrieved from https://case.edu/affil/tibet/moreTibetInfo/documents/Bilingual4.pdf

Sun, C. L. (2013). Exploring impacts of IT in language teaching in China. Theory and Practice in Language Studies, 3(8), 1479-1484. https://doi.org/10.4304/tpls.3.8.1479-1484

The Sixth Population Census of China. (2010). Retrieved from http://www.stats.gov.cn/tjsj/pcsj/rkpc/6rp/in dexch.htm

Thomas, D. R. (2006). A General Inductive Approach for Analyzing Qualitative Evaluation Data. American Journal of Evaluation, 27(2), 237-246. https://doi.org/10.1177/1098214005283748

Wu, Y. (2001). English Language Teaching in China: Trends and Challenges. TESOL Quarterly, 35(1), 191-194. https://doi.org/10.2307/3587867

Xu, Y., \& Liu, Y. (2009). Teacher Assessment Knowledge and Practice: A Narrative Inquiry of a Chinese College EFL Teacher's Experience. TESOL Quarterly, 43(3), 493-513. https://doi.org/10.1002/j.1545-7249.2009.tb0 0246.x

Yang, R., \& Wu, M. (2009). Education for ethnic minorities in China: a policy critique SA-eDUC JOURNAL, $6(2), 117-131$

Yin, R. (2003). Case study research: Design and methods. Thousand Oaks, Calif.: Sage Publications.

\section{Copyrights}

Copyright for this article is retained by the author(s), with first publication rights granted to the journal.

This is an open-access article distributed under the terms and conditions of the Creative Commons Attribution license (http://creativecommons.org/licenses/by/4.0/). 